\title{
Orthographic neighborhood size effects in recognition memory
}

\author{
Gina A. Glanc and Robert L. Greene \\ Case Western Reserve University, Cleveland, Ohio
}

\begin{abstract}
This study argues for the importance of physical word features in recognition memory by investigating the influence of orthographic distinctiveness. Experiment 1 demonstrated a mirror effect in a yes/no recognition test by manipulating orthographic neighborhood size. Words with small neighborhoods showed more hits and fewer false alarms than did words with larger neighborhoods. Experiment 2 replicated the neighborhood size mirror effect using null pairs in a forced choice recognition test. Experiment 3 required remember/know judgments in a yes/no recognition task. Experiment 4 used the same yes/no test as did Experiment 1, adding a study task that drew attention away from orthographic information in the study list. The mirror pattern disappeared with the addition of the study task.
\end{abstract}

A common assumption in memory theory is that words are represented in memory in terms of three different types of features - orthographic, phonemic, and semantic - all of which combine to form a memory representation. Whereas semantic features have long been thought to be dominant in memory, nonsemantic features are thought to have only a transient effect. This assumption is implicit in both stage models (see, e.g., Atkinson \& Shiffrin, 1968; Waugh \& Norman, 1965) and levels of processing models (Craik \& Lockhart, 1972), which emphasize the importance of semantic over nonsemantic features in creating accessible, durable memory traces.

However, semantic features may not be the only important information influencing memory. Diana, Peterson, and Reder (2004) examined the role of nonsemantic features in recognition by manipulating the frequency of fonts used in presentation of the study list. In the subsequent recognition test, low-frequency fonts showed higher hit rates as well as lower false alarm rates even though subjects had been instructed to decide only on the basis of the word, regardless of font. This is evidence that physical features do influence recollection of target words.

The orthographic distinctiveness effect, the finding that orthographically distinct words facilitate recollection, is another example of physical word features' influencing memory. As early as 1972, researchers were reporting evidence that orthographic distinctiveness increased both recognition and recall (Hirshman \& Jackson, 1997; Hunt \& Elliott, 1980; Zechmeister, 1972). "Zechmeister hypothesized that an implicit response to a "strange" or "unusual" word might be elicited by orthographic information. This response could then be stored as part of the memory for the study phase, providing an additional retrieval cue.
Recently it has been claimed that orthographic distinctiveness may be a contributing factor in the word frequency effect, which is the finding in recognition tests that words of low normative frequency (low-frequency, or LF, words) show both a higher hit rate and a lower false alarm rate than do words of high normative frequency (highfrequency, or HF, words) when presented in a mixed list (Glanzer \& Adams, 1985, 1990). Malmberg, Steyvers, Stephens, and Shiffrin (2002) investigated the hypothesis that LF words are recognized better than HF words because they contain more distinct orthographic featuresin this instance, the frequency of individual letters within words on the study list. Malmberg et al. found that words made up of primarily LF letters were recognized better than words made up of HF letters. More importantly, they found a mirror effect as a function of letter frequency: Words made up primarily of LF letters showed both higher hit rates and lower false alarm rates than did words made up primarily of HF letters.

Although early studies relied on a poll of their subject pool to report which words "looked unusual" (Hunt \& Elliott, 1980; Zechmeister, 1972), more recent studies have attempted to operationally define orthographic distinctiveness in terms of orthographic neighborhood size. An early definition provided by Coltheart, Davelaar, Jonasson, and Besner (1977) defines a target's orthographic neighborhood size as the set of words that can be made by changing only one letter of the target word while maintaining letter positions. For example, the orthographic neighborhood for the target word $d o g$ would include dig, $\operatorname{cog}$, and dot. One limitation of this definition is that it contains no reference to a word's phonology, which is also an important part of the memory representation. Recently, a more comprehen-

G.A.Glanc,gag5@cwru.edu 
sive definition of orthographic neighborhood size that includes phonology has been provided (Cortese, Watson, Wang, \& Fugett, 2004; Ziegler \& Perry, 1998). According to this definition, a target's orthographic neighborhood size consists of the number of words in the language that have the same orthographic and phonological rime as does a target word (Cortese et al., 2004). This means that a word's orthographic neighborhood consists of all the words in the language consisting of rimes that are spelled the same and sound the same as the target word. For example, the orthographic neighborhood for the word bat would be considered large (high- $N$ ) because it would include a large number of similar words such as mat, tat, cat, and so forth, but the orthographic neighborhood for the word rhyme, on the other hand, would be small (low- $N$ ) because few other words (thyme, for example) would be included.

Cortese et al. (2004) examined the effects of orthographic distinctiveness as measured by orthographic neighborhood size, using both recognition and recall tasks to investigate the hypothesis that a word is distinct because it has a unique orthographic and phonological representation in memory. The study words were equated for word frequency and word length, and the variables manipulated were orthographic neighborhood size and mapping consistency (whether a word's phonological rime has only one or multiple spellings). Their data showed that low- $N$ words were recalled at higher rates than those for high- $N$ words and exhibited higher hit rates in recognition tests, but that the effect of mapping was not significant. Cortese et al. suggested that the number of associations involved in large orthographic neighborhoods causes interference in the retrieval process. The subject easily recognizes that the particular letter pattern is attached to a word in memory, but which word is harder to determine. They also hypothesized that a mirror effect might be found as a function of orthographic neighborhood size. Although their data did show higher hit rates and lower false alarm rates for low- $N$ words, the effect of stimulus type was significant for hits but not for false alarms.

The purpose of the present study was to further investigate the role of orthographic distinctiveness, as described by orthographic neighborhood size, in recognition memory, as well as its similarity to the effects of word frequency. If orthographic distinctiveness operates similarly to word frequency, then the empirical patterns associated with word frequency in recognition memory should be observed with manipulations of orthographic neighborhood size. Four empirical patterns associated with word frequency were examined in order to test this prediction. First, a mirror effect pattern should be found as a function of orthographic distinctiveness in a typical yes/no recognition test while word frequency is held constant. Specifically, low- $N$ words would be expected to show both a higher hit rate and a lower false alarm rate than those shown by high- $N$ words. Second, a mirror effect pattern should be found as a function of orthographic distinctiveness in forced choice recognition, using null pairs to focus on the relationship between the word classes by holding old/new status constant. Here, one would expect to find higher proportions of high- $N$ words chosen when both test items were new, and higher proportions of low- $N$ words chosen when both test items were old. Third, if the mirror effect is caused by better recollection due to the distinctiveness of low- $N$ words, then, in a remember/know paradigm, low- $N$ words should receive a larger number of $r e$ member responses, whereas high- $N$ words should receive a larger number of know responses. Finally, if the orthographic distinctiveness effect is the driving factor for the mirror effect, then the hit rates for low- $N$ words should be attenuated when a semantic orienting task is used during the study phase, as happens with word frequency (Criss \& Shiffrin, 2004; Hilford, Glanzer, \& Kim, 1997; Hirshman \& Arndt, 1997).

\section{EXPERIMENT 1}

The purpose of the first experiment was to display the same mirror effect pattern that occurs when one manipulates word frequency, by instead manipulating orthographic distinctiveness as measured by orthographic neighborhood size. (In the present study, we define orthographic neighborhood as a group of words that share the same orthographical and phonological rime.) A word frequency effect typically occurs in memory studies using a standard yes/no recognition procedure (Glanzer \& Adams, 1990; Glanzer, Adams, Iverson, \& Kim, 1993). If orthographic distinctiveness, as measured by neighborhood size, behaves similarly to word frequency, then a mirror pattern should appear with this experimental manipulation as well. According to the hypothesis, low- $N$ words should show both a higher hit rate and a lower false alarm rate than those shown by high- $N$ words.

\section{Method}

Participants. Twenty-three students from introductory psychology classes participated to fulfill a class requirement.

Design. A $2 \times 2 \times 2$ repeated measures design was used, with word status (old vs. new), orthographic neighborhood size (high- $N$ vs. low- $N$ ), and mapping (consistent vs. inconsistent) as factors. The dependent variable measured was the number of positive yes responses.

Mapping is considered here because, although it has been shown to facilitate lexical decision (Ziegler \& Perry, 1998), the effects of mapping on memory have been less well studied and the findings have often been contradictory (Cortese et al., 2004; Hirshman \& Jackson, 1997). Consistency is measured according to the number of spellings that the target word's orthographic rime can be mapped onto. If a target word is consistent, its phonological rime can be mapped onto only one spelling pattern. Inconsistent words can be mapped onto more than one spelling pattern. (See Ziegler, Stone, \& Jacobs' [1997] definition of "feedback consistency.") We chose this definition of mapping consistency over others, because the main variable considered here was orthographic spelling patterns.

Materials. The stimuli consisted of 116 monosyllabic words, all equated for word length and normative frequency according to standards set by Kučera and Francis (1967). The mean word length was 4.23 letters, and the mean word frequency was 71.01. Orthographic neighborhood size and mapping consistency were determined according to Ziegler et al. (1997). The high- $N$ word group included only words with 6 or more neighbors (mean orthographic neighborhood size, 12.13), whereas the low- $N$ word group included only words with 3 or fewer neighbors (mean orthographic neighborhood size, 1.25). A full list of the stimuli and mean word characteristics can be found in Appendixes A and B. 
Procedure. The study list consisted of 68 words, which were divided into 24 high- $N$ words (half with consistent mapping and half with inconsistent mapping), 24 low- $N$ words (also half with consistent mapping and half with inconsistent mapping), and 20 primacy/recency buffers that were not tested. The assignment of stimuli to old/new status and presentation order were randomized for each participant. The study items were randomly intermixed and presented on a computer screen at a rate of 1 word per second. Participants were instructed to pay equal attention to each word as it appeared on the screen and were informed that a memory test for the study list would follow. Immediately following list presentation, participants were given a 96-item yes/no recognition test in which half of the items were old and half new. Participants were instructed to press one key if the test word had appeared on the study list and a different key if it had not appeared on the list.

\section{Results and Discussion}

The mean proportions of positive responses are shown in Table 1. An alpha level of .05 was used as the standard of significance for all tests, unless otherwise stated. A mirror effect was found, with low- $N$ words showing both higher hit rates $(M=.70)$ and lower false alarm rates $(M=.19)$ than those for high- $N$ words $(M=.64$ and .24 , respectively). An ANOVA on numbers of positive responses found a significant main effect of item status (old vs. new) $\left[F(1,25)=238.74, M S_{\mathrm{e}}=1,551.08\right]$; however, the main effects of neighborhood size and mapping were not significant $[F(1,25)=0.12$ and $F(1,25)=0.07$, respectively]. Importantly, a significant interaction between item status and neighborhood size $\left[F(1,25)=8.78, M S_{\mathrm{e}}=8.70\right]$ was found. The data showed the predicted reversal of hit rates and false alarm rates that indicates the presence of a mirror effect. Unlike in the Cortese et al. (2004) study, which revealed a significant effect of stimulus type for hits only when hits and false alarms were analyzed separately, the effect of neighborhood size in the present study was significant for both hits $\left[F(1,25)=6.60, M S_{\mathrm{e}}=27.77\right]$ and false alarms $\left[F(1,25)=4.38, M S_{\mathrm{e}}=17.31\right]$ when these were analyzed separately. It is important to note that the results of the present study replicate the neighborhood size effect found by Cortese et al. and extend it to a different set of stimuli.

\section{EXPERIMENT 2}

The word frequency effect has also been demonstrated using a forced choice recognition procedure (Glanzer \& Adams, 1990; Glanzer et al., 1993; Glanzer \& Bowles, 1976; Kim \& Glanzer, 1993). The present Experiment 2 was an attempt to find a mirror effect as a function of orthographic neighborhood size using a forced choice recognition test, thus providing evidence for the generality of the orthographic distinctiveness effect.
The use of null pairs has been used effectively to investigate the relationship between HF and LF word classes. In a standard forced choice recognition procedure, given two word classes (HF and LF), test pairs can be used to make the following comparisons: HF old words versus $\mathrm{HF}$ new words, LF old words versus LF new words, HF old words versus LF new words, and LF old words versus HF new words. However, these combinations can be affected not only by word frequency, but also by item status (old or new). The use only of null pairs gives a more accurate description of the relationship between the HF and LF word classes and item status by holding item status constant (Glanzer \& Bowles, 1976).

In this experiment, null pairs consisting of two words, both of which were either presented on the study list or not presented, were used to give further information about the relationship between orthographic neighborhood size classes and item status by holding item status (old/new) constant. The results from this type of manipulation provide a logical equivalent to the interaction between item status and orthographic neighborhood size used in the previous experiment.

\section{Method \\ Participants. Twenty-nine students from introductory psychol- ogy classes participated to fulfill a class requirement. \\ Design. A $2 \times 2$ repeated measures design was used, with item status (old vs. new) and orthographic neighborhood size (high- $N$ vs. low- $N$ ) as factors. The dependent variable measured was the propor- tion of times that the low- $N$ word was chosen over the high- $N$ word. \\ Materials. These were the same as those for Experiment 1. \\ Procedure. The same list presentation procedure was used as in the previous experiment. Immediately following list presentation, participants were given a forced choice recognition test with 48 test pairs in which both words were either previously presented or new. Participants were instructed to choose which of the two words in the test pair had occurred previously during the study session.}

\section{Results and Discussion}

The dependent variable was the proportion of test trials on which the participant chose the low- $N$ word rather than the high- $N$ word. The proportion of trials on which participants selected the low- $N$ word is shown in Table 2 as a function of item status (old/new) and mapping (consistent/inconsistent).

An ANOVA on the number of times that the low- $N$ word was chosen over the high- $N$ word found a significant main effect for item status (old vs. new) $[F(1,28)=8.96$, $\left.M S_{\mathrm{e}}=43.46\right]$. As in the previous experiment, the main effect of mapping was not significant $[F(1,28)=1.15]$. When both items in the test pair were old, the low- $N$ word class was chosen more often $(55 \%)$ than the high- $N$ word class $(45 \%)$. When both items in the test pair were new,

Table 1 Mean Proportions of Positive Responses in Experiment 1

\begin{tabular}{lcccccc}
\hline & \multicolumn{2}{c}{ Old Items (Hit Rate) } & & \multicolumn{2}{c}{ New Items (False Alarm Rate) } \\
\cline { 2 - 3 } \cline { 5 - 6 } & High $N$ & Low $N$ & & High $N$ & Low $N$ \\
\hline Consistent mapping & .62 & .70 & & .24 & .19 \\
Inconsistent mapping & .65 & .70 & & .24 & .19 \\
\hline
\end{tabular}


Table 2

Proportion of Low- $N$ Over High- $N$ Responses in Experiment 2

\begin{tabular}{lcc}
\hline & Old Items & New Items \\
\hline Consistent mapping & .55 & .47 \\
Inconsistent mapping & .54 & .42
\end{tabular}

however, the high- $N$ word class was chosen more often as "old" ( $56 \%$ vs. $44 \%$ for low- $N$ words). The reversal of selection indicates a mirror effect. The mean number of low- $N$ items chosen in both conditions was significantly different from chance $[t(28)=2.22$, old item null pairs; $t(28)=2.28$, new item null pairs].

\section{EXPERIMENT 3}

This experiment was designed to further investigate the interaction between orthographic neighborhood size and item status shown in Experiment 1 by extending the design to include a remember/know paradigm. In word frequency studies, different levels of normative frequency show different patterns of remember and know responses in addition to an overall mirror effect. Specifically, LF targets tend to receive more remember responses than do HF targets, whereas HF targets tend to receive more know responses than do LF targets (Joordens \& Hockley, 2000; Reder et al., 2000). The theoretical interpretation of remember/know data is controversial (see, e.g., Donaldson, 1996; Dunn, 2004; Gardiner \& Richardson-Klavehn, 2000). However, the purpose of Experiment 3 was purely empirical - namely, to determine whether a manipulation of orthographic neighborhood size would yield the same pattern as that found in manipulations of word frequency. According to the hypothesis that orthographic distinctiveness plays a role in the word frequency effect, orthographic neighborhood size should reflect the same patterns. In addition to low- $N$ words' showing both a higher hit rate and a lower false alarm rate than those for high- $N$ words (an overall mirror effect), low- $N$ words should receive more remember responses than those for high- $N$ words, whereas high- $N$ words should receive more know responses than those for low- $N$ words.

\section{Method}

Participants. Forty-four students from introductory psychology classes participated to fulfill a class requirement.

Design. As in Experiment 1, a $2 \times 2 \times 2$ repeated measures design was used, with word status (old vs. new), orthographic neighborhood size (high- $N$ vs. low- $N$ ), and mapping (consistent vs. inconsistent) as factors. The dependent variable was the number of positive yes responses. The number of yes responses was then divided into two categories: remember and know.

Materials. These were the same as in Experiment 1.

Procedure. The list presentation procedure was the same as in Experiment 1 . Immediately following list presentation, participants were given a 96-item yes/no recognition test in which half of the items were old and half new. Instructions were given to press one key if the test word had appeared previously on the study list and press a different key if it had not appeared on the list. In addition, when participants indicated that they had seen a word on the study list, they were asked to further indicate whether they made the choice on the basis of conscious recollection by pressing a key for remember, or overall familiarity of the item in the absence of conscious recollection by pressing a separate key for know. Participants were instructed to include guesses by pressing the know key. Definitions of remember and know responses were given in the instructions, which followed closely those presented by Gardiner and RichardsonKlavehn (2000).

\section{Results and Discussion}

Separate ANOVAs were conducted on the overall number of positive responses as well as the number of remember and know responses.

Overall positive responses. The mean proportions of overall positive responses are shown in Table 3. As in Experiment 1 , an overall mirror effect was found, with low- $N$ words showing both higher hit rates $(M=.65)$ and lower false alarm rates $(M=.22)$ than those for high- $N$ words $(M=.59$ and .28 , respectively). A significant main effect of item status (old vs. new) was found $[F(1,43)=409.97$, $\left.M S_{\mathrm{e}}=1,737.28\right]$ as well as a significant interaction between item status and neighborhood size $[F(1,43)=$ $\left.11.97, M S_{\mathrm{e}}=54.10\right]$. The effect of neighborhood size was significant for both hits $\left[F(1,43)=5.37, M S_{\mathrm{e}}=58.91\right]$ and false alarms $\left[F(1,43)=9.44, M S_{\mathrm{e}}=49.50\right]$.

Remember responses. The mean proportions of remember responses are shown in Table 3. A larger number of remember responses were made to low- $N$ words $(M=$ $.50)$ than to high- $N$ words $(M=.38)$. Significant main effects were found for neighborhood size $[F(1,43)=12.43$, $\left.M S_{\mathrm{e}}=38.89\right]$ and item status $\left[F(1,43)=186.11, M S_{\mathrm{e}}=\right.$ 1,081.50]. A significant interaction was found between neighborhood and item status $\left[F(1,43)=17.60, M S_{\mathrm{e}}=\right.$ 61.39]. The differences in numbers of remember responses for high- $N$ and low- $N$ words were seen only for old items. This may result from a floor effect on false alarms.

Know responses. The mean proportions of know responses are shown in Table 3. A larger number of know responses was made for high- $N$ words $(M=.48)$ than for low- $N$ words $(M=.38)$. Significant main effects were found for neighborhood size $\left[F(1,43)=12.03, M S_{\mathrm{e}}=\right.$ $35.00]$ and item status $\left[F(1,43)=16.08, M S_{\mathrm{e}}=79.23\right]$. Unlike for the remember responses, there was no significant interaction between neighborhood and item status $(F=.06)$. The higher number of know responses was present for both new and old items.

Table 3

Mean Proportion of Positive Responses in Experiment 3

\begin{tabular}{|c|c|c|c|c|}
\hline & \multicolumn{2}{|c|}{$\begin{array}{l}\text { Old Items } \\
\text { (Hit Rate) }\end{array}$} & \multicolumn{2}{|c|}{$\begin{array}{c}\text { New Items } \\
\text { (False Alarm Rate) }\end{array}$} \\
\hline & $\operatorname{High} N$ & Low $N$ & $\operatorname{High} N$ & Low $N$ \\
\hline \multicolumn{5}{|l|}{ Overall } \\
\hline Consistent mapping & .58 & .65 & .28 & .21 \\
\hline Inconsistent mapping & .59 & .65 & .28 & .22 \\
\hline \multicolumn{5}{|l|}{ Remember } \\
\hline Consistent mapping & .31 & .43 & .08 & .06 \\
\hline Inconsistent mapping & .29 & .43 & .08 & .07 \\
\hline \multicolumn{5}{|l|}{ Know } \\
\hline Consistent mapping & .27 & .22 & .20 & .15 \\
\hline Inconsistent mapping & .29 & .23 & .20 & .15 \\
\hline
\end{tabular}


In accordance with the hypothesis, the data show the predicted reversal of hit rates and false alarm rates that indicates the presence of an overall mirror effect and, in addition, remember responses contained a larger proportion of low- $N$ words, whereas know responses contained a larger proportion of high- $N$ words.

\section{EXPERIMENT 4}

The previous three experiments provide support for a physical feature-based mirror effect. If attention to orthographic distinctiveness is in fact the underlying factor for this mirror pattern, then drawing attention away from this information should reduce or eliminate the pattern. Experiment 4 was an attempt to demonstrate this using the same yes/no recognition test used in Experiment 1. A task was added at study to draw attention away from physical word features and thus decrease the memory advantage that this information provided. This should result in a reduction of the hit rate advantage for low- $N$ words, eliminating the mirror pattern. The same manipulation has been done in word frequency studies and was successful in eliminating the mirror pattern by reducing the hit rate advantage for LF words (Criss \& Shiffrin, 2004; Guttentag \& Carroll, 1994; Hirshman \& Arndt, 1997).

\section{Method}

Experiment 4 utilized the same design and materials as in Experiment 1.

Participants. Twenty-three students from introductory psychology classes participated to fulfill a class requirement.

Procedure. The same basic procedure was used as in Experiment 1 , with one exception. Participants were asked to answer out loud, during presentation of the study list, the following question for each word as it appeared on the screen: "Does this item represent something that is living?" (This "animacy" question was used in Criss \& Shiffrin, 2004.) Immediately following list presentation, the participants were given the same 96-item yes/no recognition test as in Experiment 1. Instructions were given to press one key if the test word had appeared previously on the study list, and a different key if it had not appeared on the list.

\section{Results and Discussion}

The mean proportions of positive responses are shown in Table 4. An ANOVA on numbers of positive responses found a significant main effect of item status (old vs. new) $\left[F(1,19)=919.00, M S_{\mathrm{e}}=2,220.10\right]$; however, the main effects of neighborhood size and mapping were not significant $[F(1,19)=1.36$ and $F(1,19)=3.82$, respectively].

As in the first experiment, a significant interaction between item status and neighborhood size $[F(1,9)=$ $\left.4.93, M S_{\mathrm{e}}=4.23\right]$ was found. The likelihood of a subject responding "yes" to an old item (hit) was the same for low- $N$ words as for high- $N$ words (78\%). The likelihood of a subject responding "yes" to a new item (false alarm), however, was greater for high- $N$ words $(19 \%)$ than for low- $N$ words (14\%). There was no reversal of hit and false alarm rates like that seen in the previous two experiments; thus, no mirror effect was found. As in Criss and Shiffrin's (2004) results, the hit rate pro-
Table 4

\begin{tabular}{lccccc}
\multicolumn{2}{c}{ Mean Proportions of Positive Responses in Experiment $\mathbf{4}$} \\
\hline & \multicolumn{2}{c}{$\begin{array}{c}\text { Old Items } \\
\text { (Hit Rate) }\end{array}$} & & \multicolumn{2}{c}{$\begin{array}{c}\text { New Items } \\
\text { (False Alarm Rate) }\end{array}$} \\
\cline { 2 - 3 } & High $N$ & Low $N$ & & High $N$ & Low $N$ \\
\hline Consistent mapping & .76 & .78 & & .20 & .11 \\
Inconsistent mapping & .80 & .79 & & .18 & .16 \\
\hline
\end{tabular}

portions were altered with the addition of an orienting task, while the false alarm pattern stayed relatively the same as in the first experiment. The mirror pattern thus disappeared, with the experimental manipulation drawing attention away from orthographic information, supporting the hypothesis that the mirror effect pattern seen here was due to orthographic distinctiveness. When hits and false alarms were analyzed separately, the effect of neighborhood size was significant for false alarms $\left[F(1,19)=4.65, M S_{\mathrm{e}}=4.65\right]$ but not for hits $[F(1,19)=$ $\left.0.01, M S_{\mathrm{e}}=3.66\right]$.

\section{GENERAL DISCUSSION}

The main purpose of the present study was to investigate the effects of orthographic distinctiveness, as defined by orthographic neighborhood size, on memory. Results from Experiment 1 showed the expected mirror pattern in a standard yes/no recognition test. In Experiment 2, we further explored the generality of the mirror effect using a forced choice recognition test. Null pairs were used to eliminate effects of item status, and the expected mirror pattern again occurred. Experiment 3 further demonstrated the orthographic distinctiveness hypothesis by showing higher proportions of remember responses for low- $N$ words and higher proportions of know responses for high- $N$ words, in addition to an overall mirror effect pattern. Experiment 4 demonstrated that drawing attention away from orthographic information by instituting a semantic-processing task at study prevents the mirror effect from appearing.

\section{Role of Orthographic Distinctiveness in Memory}

The results of these experiments add to the growing body of research on orthographic information and the recognition process. The orthographic distinctiveness effect in memory is a clear case of facilitation caused by nonsemantic features. This effect argues against the notion that nonsemantic information such as orthography and phonology has only a transient effect on memory retention (Craik \& Lockhart, 1972).

When memory recollection was manipulated in Experiment 4 by introducing a study task, the hit rate advantage for low- $N$ words was eliminated, but the high false alarm rate for the more familiar high- $N$ words remained the same. One way to explain this pattern may be found in the dual-process approach to recognition (Cary \& Reder, 2003; Joordens \& Hockley, 2000), which sees recognition performance as being based on both familiarity and episodic recollection. According to this theory, episodic 
recollection is the process responsible for the difference between hit rates and false alarm rates that is seen in the mirror effect. An explanation of the orthographic distinctiveness effect made according to such models would argue that interference from coactivation of orthographic patterns shared with neighbors may hinder the episodic recollection of high- $N$ words, resulting in lower hit rates for these words during a recognition test. The same coactivations, however, make high- $N$ words seem more familiar in general, resulting in higher false alarm rates in the same test, creating a typical mirror effect (Cortese et al., 2004). The pattern of results from Experiment 3 would seem to support this theory, because a larger number of remember responses were made for the more distinct low- $N$ words, whereas a larger number of high- $N$ words were included in the know responses, which reflect overall familiarity.

A second explanation may be given by single-process theorists who argue that recognition decisions are made according to a continuous familiarity dimension on the basis of a match between the memory for the study list and a test item (Criss \& Shiffrin, 2004; Malmberg et al., 2002). These theorists would argue that the interference caused by the large number of coactivations for old high- $N$ words lowers the confidence level used to make the recognition decision, because there is a higher chance that a feeling of familiarity may be caused by coactivations rather than an actual match. This would cause lower hit rates for old high- $N$ words but would also increase the confidence level for new high- $N$ words, resulting in higher false alarm rates. The remember/know differences seen in Experiment 3 can be explained by dividing the positive responses according to a second confidence criterion (Donaldson, 1996; Dunn, 2004). Remember responses may be considered as positive responses with a higher confidence level than that for positive know responses.

\section{Orthographic Distinctiveness and Word Frequency}

The results provide evidence that the effects of orthographic distinctiveness may resemble those of word frequency in recognition studies. Each of the four experiments took an empirical result associated with word frequency and demonstrated that a comparable finding could be obtained by manipulating orthographic distinctiveness.

Most of the evidence considered in this discussion supports the hypothesis that the mirror effect is caused by a balance between familiarity and conscious recollection. If this balance is disturbed, the mirror pattern does not occur. Furthermore, conscious recollection can be influenced by item distinctiveness. The experiments performed in this study demonstrate that orthographic neighborhood size is one important component that influences distinctiveness. Words sharing few orthographic neighbors are more distinctive than words with larger neighborhoods, and therefore they may be easier to recollect. This recollection advantage increases the hit rates for low- $N$ words, while at the same time lowering the false alarm rate and creating the typical mirror pattern that has been seen for word frequency.

\section{AUTHOR NOTE}

Correspondence should be addressed to G. A. Glanc, Department of Psychology, Case Western Reserve University, 10900 Euclid Avenue, Cleveland, OH 44106-7123 (e-mail: gag5@cwru.edu).

\section{REFERENCES}

AtKinson, R. C., \& Shiffrin, R. M. (1968). Human memory: A proposed system and its control processes. In K. W. Spence \& J. T. Spence (Eds.), The psychology of learning and motivation: Advances in research and theory (Vol. 2, pp. 90-195). New York: Academic Press.

CARY, M., \& Reder, L. M. (2003). A dual-process account of the listlength and strength-based mirror effects in recognition. Journal of Memory \& Language, 49, 231-248.

Coltheart, M., Davelaar, E., Jonasson, J. T., \& Besner, D. (1977). Access to the internal lexicon. In S. Dornic (Ed.), Attention and performance VI (pp. 535-555). Hillsdale, NJ: Erlbaum.

Cortese, M. J., Watson, J. M., Wang, J., \& Fugett, A. (2004). Relating distinctive orthographic and phonological processes to episodic memory performance. Memory \& Cognition, 32, 632-639.

Craik, F. I. M., \& Lockhart, R. S. (1972). Levels of processing: A framework for memory research. Journal of Verbal Learning \& Verbal Behavior, 11, 671-684

Criss, A. H., \& ShIFFrin, R. M. (2004). Interactions between study task, study time, and the low-frequency hit rate advantage in recognition memory. Journal of Experimental Psychology: Learning, Memory, \& Cognition, 30, 778-786.

Diana, R. A., Peterson, M. J., \& Reder, L. M. (2004). The role of spurious feature familiarity in recognition memory. Psychonomic Bulletin \& Review, 11, 150-156.

DonaldSON, W. (1996). The role of decision processes in remembering and knowing. Memory \& Cognition, 24, 523-533.

DunN, J. C. (2004). Remember-know: A matter of confidence. Psychological Review, 111, 524-542.

Gardiner, J. M., \& RichardSON-KLAVEhn, A. (2000). Remembering and knowing. In E. Tulving \& F. I. M. Craik (Eds.), The Oxford handbook of memory (pp. 229-244). Oxford: Oxford University Press.

Glanzer, M., \& ADAMS, J. K. (1985). The mirror effect in recognition memory. Memory \& Cognition, 13, 8-20.

Glanzer, M., \& Adams, J. K. (1990). The mirror effect in recognition memory: Data and theory. Journal of Experimental Psychology: Learning, Memory, \& Cognition, 16, 5-16.

Glanzer, M., Adams, J. K., Iverson, G. J., \& Kim, K. (1993). The regularities of recognition memory. Psychological Review, 100, 546-567.

Glanzer, M., \& Bowles, N. (1976). Analysis of the word-frequency effect in recognition memory. Journal of Experimental Psychology: Human Learning \& Memory, 2, 21-31.

Guttentag, R. E., \& Carroll, D. (1994). Identifying the basis for the word frequency effect in recognition memory. Memory, 2, 255-273.

Hilford, A., GlanZer, M., \& Kim, K. (1997). Encoding, repetition, and the mirror effect in recognition memory: Symmetry in motion. Memory \& Cognition, 25, 593-605.

Hirshman, E., \& ARnDT, J. (1997). Discriminating alternative concepts of false recognition: The cases of word concreteness and word frequency. Journal of Experimental Psychology: Learning, Memory, \& Cognition, 23, 1306-1323.

Hirshman, E., \& JACKSON, E. (1997). Distinctive perceptual processing and memory. Journal of Memory \& Language, 36, 2-12.

Hunt, R. R., \& Elliott, J. M. (1980). The role of nonsemantic information in memory: Orthographic distinctiveness effects on retention. Journal of Experimental Psychology: General, 109, 49-74.

Joordens, S., \& HocKLEY, W. E. (2000). Recollection and familiarity through the looking glass: When old does not mirror new. Journal of Experimental Psychology: Learning, Memory, \& Cognition, 26, $1534-1555$.

Kim, K., \& Glanzer, M. (1993). Speed versus accuracy instructions, study time, and the mirror effect. Journal of Experimental Psychology: Learning, Memory, \& Cognition, 19, 638-652.

KuČERA, H., \& FrancIS, W. N. (1967). Computational analysis of 
present-day American English. Providence, RI: Brown University Press.

Malmberg, K. J., Steyvers, M., Stephens, J. D., \& Shiffrin, R. M. (2002). Feature frequency effects in recognition memory. Memory \& Cognition, 30, 607-613.

Reder, L. M., Nhouyvanisvong, A., Schunn, C. D., Ayers, M. S., Angstadt, P., \& Hiraki, K. (2000). A mechanistic account of the mirror effect for word frequency: A computational model of remember-know judgments in a continuous recognition paradigm. Journal of Experimental Psychology: Learning, Memory, \& Cognition, 26, 294-320.
Waugh, N. C., \& Norman, D. A. (1965). Primary memory. Psychological Review, 72, 89-104.

ZECHMEISTER, E. B. (1972). Orthographic distinctiveness as a variable in word recognition. American Journal of Psychology, 85, 425-430.

Ziegler, J. C., \& Perry, C. (1998). No more problems in Coltheart's neighborhood: Resolving neighborhood conflicts in the lexical decision task. Cognition, 68, B53-B62.

Ziegler, J. C., Stone, G. O., \& Jacobs, A. M. (1997). What is the pronunciation for -ough and the spelling for $/ \mathrm{u} /$ ? A database for computing feedforward and feedback consistency in English. Behavior Research Methods, Instruments, \& Computers, 29, 600-618.

APPENDIXA

Words Used in Experiments

\begin{tabular}{|c|c|c|c|c|}
\hline \multicolumn{5}{|c|}{$\operatorname{High} N$, Consistent } \\
\hline Grab & Bench & Job & Jump & Sound \\
\hline Bag & Brick & Wrong & Club & Bunch \\
\hline Draft & Slid & Duck & Took & Boy \\
\hline Gang & Pig & Bust & Quit & Lift \\
\hline Bell & Bring & Boil & Rug & \\
\hline \multicolumn{5}{|c|}{ Low $N$, Consistent } \\
\hline Bulk & Rev & Six & World & Elk \\
\hline Porch & Lodge & Step & Fax & Lens \\
\hline Yeah & Vague & Pulse & Glimpse & Void \\
\hline Save & Babe & Bulb & Faith & Bulge \\
\hline Midst & Month & Else & Width & \\
\hline \multicolumn{5}{|c|}{ High $N$, Inconsistent } \\
\hline Cake & Trunk & Fail & Bee & Bride \\
\hline Flame & Pain & Bed & Deep & Trend \\
\hline Track & Saw & Drink & Speed & Dice \\
\hline Date & Male & Joke & Lung & Bet \\
\hline Glass & Bay & Gum & Dry & \\
\hline \multicolumn{5}{|c|}{ Low $N$, Inconsistent } \\
\hline Waist & Gauge & Search & Firm & Curve \\
\hline Graph & Meant & Yes & Herd & Gulf \\
\hline Arc & Peace & Heart & Eve & Soap \\
\hline Staff & Straight & Debt & Egg & Curb \\
\hline Jazz & False & Teeth & Sleeve & \\
\hline \multicolumn{5}{|c|}{ Buffers } \\
\hline Niche & Knight & Quest & Morgue & Yacht \\
\hline Quell & Lawn & Serf & Mast & Suds \\
\hline Pink & Halt & Wench & Gem & Wheat \\
\hline Catch & Bard & Rod & Doll & Gist \\
\hline
\end{tabular}

APPENDIX B

Word Characteristics (Means)

\begin{tabular}{lccc}
\hline $\begin{array}{c}\text { Orthographic } \\
\text { Neighborhood }\end{array}$ & $\begin{array}{c}\text { Normative Word } \\
\text { Frequency }\end{array}$ & $\begin{array}{c}\text { Word } \\
\text { Length }\end{array}$ & $\begin{array}{r}\text { Number of } \\
\text { Neighbors }\end{array}$ \\
\hline High/consistent & 77.875 & 4.083 & 10.625 \\
Low/consistent & 77.708 & 4.291 & 1.500 \\
High/inconsistent & 65.625 & 3.958 & 13.625 \\
Low/inconsistent & 62.833 & 4.583 & 1.000 \\
\hline
\end{tabular}

(Manuscript received September 25, 2005;

revision accepted for publication February 8, 2006.) 